"This is the peer reviewed version of the following article: [A geography of residents' worry about the disruptive effects of contaminated sites |

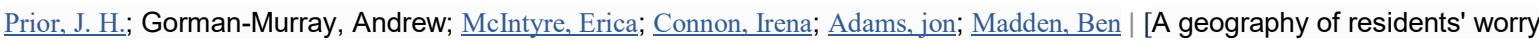
about the disruptive effects of contaminated sites], which has been published in final form at [10.1111/1745-5871.12312]

This article may be used for non-commercial purposes in accordance with Wiley Terms and Conditions for Self-Archiving 


\section{A geography of residents' worry about the disruptive effects of contaminated sites}

\section{Submission to: Geographical Research, Health Geography special issue}

Abstract: Whilst the link between contaminated sites and adverse effects on human health and wellbeing are being increasingly recognised, some argue that the magnitude of the health problem is inadequately addressed because it is largely invisible. Health geographies literature has sought to highlight this invisibility by focusing on the link between contaminated sites and health. This study adds to health geographies by presenting unique insights into the geography of residents' worry about the disruptive effect of environmental contamination on health and wellbeing. It analyses a sample of residents $(n=485)$ living near 13 contaminated sites across Australia. Ordinal logistic regression analysis of closedformat survey questions was combined with coding of open-ended survey questions to reveal the geography of residents' worry about contamination from nearby sites. First, the study explores some of the main relationships between residents, their environs, and contaminants from nearby source sites, which determines their levels of worry: residents' demographics; residents' proximity to sites; contaminant boundaries and borders; and type of contaminant. Second, the study investigates how worry affects residents' health and wellbeing, ranging from effects on their personal functioning through to their sense of ontological security, which depends in part upon their perceptions of contaminants' impacts.

Keywords: health; wellbeing; contaminated sites; worry; residents; Australia

\section{Introduction}

'Place matters' to health and wellbeing (Kearns and Gesler, 1998; Kearns and Moon, 2002, p.610), which is palpable in relation to contaminated sites. Recent estimates suggest that 61 million people are exposed to heavy metals and toxic chemicals from contaminated sites across the globe (Landrigan et al., 2018, p.18), which have killed tens of thousands of people and injured hundreds of thousands more (Landrigan et al., 2015, p.1429). To redress the exposure to human health risks from these sites, governments and industries are proposing to remediate millions of contaminated sites over the next few decades across the European Union (European Environment Agency, 2014), the United States (United States Environment Protection Agency, 2016), China (Hou and Li, 2017), and Australia (Carbonell, 2013).

While the link between contaminated sites and adverse effects on human health are increasingly recognised, some argue that the magnitude of the health problem is inadequately 
addressed because it is largely invisible (Landrigan et al., 2015; Landrigan et al., 2018, p.4). Geographers have sought to redress this invisibility. Spanning from medical to health geographies, their work has focused on the effect of environmental contamination on health and wellbeing. Medical geographers have focused on the biomedical modelling of the effects of environmental contaminants, such as lead and arsenic, on the health of populations, tracing the spread of morbidity and mortality in physical space (Cotter and Patrick, 1981; Eakin et al., 2010; Escamilla et al., 2013; Flörke et al., 2013; Hinchliffe, 2001; Loyd, 2009; Meade, 1976; Scott et al., 2012; Smallman-Raynor and Cliff, 2008; Xu et al., 2006). Health geographers have sought to extend research beyond biomedical modelling (Kearns and Moon, 2002, p.606) by drawing attention to the disruptive effects of environmental contamination and by boosting interest in broader socioecological models of health (Cotter and Patrick, 1981; Cutter, 1995; Few and Tran, 2010; Holifield, 2012; Loyd, 2009; Mansfield, 2012; Sultana, 2012). These models embrace a wide understanding of health that encompasses the concept of wellbeing, and that is associated with 'human flourishing' (Fleuret and Atkinson, 2007, p.109) and 'optimal psychological experience and functioning' (Deci and Ryan, 2008, p.1). On this basis, Kearns and Moon (2002, p.609) contend 'geographies of health are centrally about the emerging importance of place in the study of health and ... are, in part at least, medical geography's cultural turn'.

Extending health geographies research exploring the effect of contaminated sites, this paper presents findings from a unique study on how residents living near contaminated sites worry about environmental contamination from nearby source sites; how their worries impact their health and wellbeing; and how these worries cannot be discussed apart from lived relationships within their environs. As Sultana (2012) argues in examining 'contaminated citizens' in Bangladesh, contamination cannot be examined as an isolated physical issue. Our study, likewise, explores the geography of residents' worries about contaminants in their local area, including in relation to perceived disruptions to health and wellbeing. While previous studies have examined residents' worries about the application of remediation technologies to nearby contaminated sites (Prior et al., 2017), it remains to be determined how and to what extent residents' worry about contamination from nearby industrial, mining, and other sites affects their health and wellbeing.

Worry is a cognitive state (Hirsch and Mathews, 2012) with an emotional dimension (Ferrer et al., 2012; McQueen et al., 2008), constituted by a 'chain of thoughts and images, negatively affect-laden and relatively uncontrollable', which are an attempt 'to engage in 
mental problem-solving on an issue whose outcome is uncertain but contains the possibility of one or more negative outcomes' (Borkovec et al., 1983; Prior et al., 2017). Worry has significant implications for general health and wellbeing, with higher levels of worry linked to direct and indirect negative health and quality of life impacts, which may or may not manifest physiologically (Andrea et al., 2004; Brosschot et al., 2006; Keyes and Simoes, 2012). For instance, worry is a core feature of anxiety, and more likely to become pathological in uncertain situations with potentially negative outcomes, as in the case of environmental contamination (Hirsch and Mathews, 2012). The focus on worry in the more general form within this study is important - as opposed to consideration of specific disorders or stress-related symptoms - in that it provides insight into the wider health-related impacts of environmental contamination and fosters a deeper understanding of the relations between the environment and human health and wellbeing. Having insights into general forms of worry may help prevent more pervasive pathological worry among residents, and provides those involved with contamination land management with an understanding of how worry might be engaged with rather than ignored.

Health geographies have increasingly moved towards socioecological approaches to health, with the most recent approaches focusing on human flourishing rather than on physical or mental health per se (Bickerstaff and Walker, 2003; Davis, 2005; Kearns and Moon, 2002; Sultana, 2012). Some such research explores the relations between environmental hazards and worry, and makes interesting contributions to this discipline, conceptualizing worry as related to, but distinct from perceived risk, and merging the physical and mental healthrelated aspects of human flourishing (Kwan, 2012). Furthermore, worry is also an important consideration in contemporary 'risk' societies, as 'human beings are future-oriented and uncertainty about the future can negatively affect people's thoughts, emotions and behaviours' (Prior et al., 2017, p.883).

The geography of worry presented in this paper derives from the analysis of a survey of residents $(\mathrm{n}=485)$ living near 13 contaminated sites across Australia. First, ordinal logistic regression analysis of closed format survey questions is used to identify key determinants of the residents' worry about contamination from nearby sites. Second, coding of open-ended survey questions provides insights into the effect of worry on their wellbeing. Third, we outline our conceptual approach for the geography of worry, based on a review of geographical literature at the intersection of contamination and health, and then describe our 
methods and findings. The paper concludes with a discussion of the findings in the context of the broader literature.

\section{Conceptualising a geography of worry}

The conceptual framework for a geography of worry presented in this section (Figure 1) builds on, and synthesizes, a great deal of research into worry and hazards, and draws on prior health geographies research focused on contaminated sites. In conceptualising the geography of worry, we are interested in those factors that affect residents' levels of worry about the contamination from nearby source sites, and also in understanding the focus of their worry and how worry affects their wellbeing.

[Insert Figure 1 here]

\section{Figure 1: Overview of geography of residents' worry about contamination from nearby source sites}

As a negative force, worry may have psychological and physiological manifestations that impact on human health and wellbeing (Andrea et al., 2004; Brosschot et al., 2006), ranging from the adoption of a pessimistic outlook or pervasive pathological worry that can lead to fatigue, irritability, muscle tension, or sleeping disturbance (Andrea et al., 2004; Borkovec, 1994; Davey, 1994). We understand that worry can have adverse effects over time on a person's health, not only affecting their physical health but also their ability to 'flourish' (Fleuret and Atkinson, 2007; Stefanovic, 2008). This effect is because a person's well-being - their ability to flourish and optimally operate - and their everyday lifeworld mutually presuppose and afford each other (Malpas, 1999; Stefanovic, 2008). The need for a safe and secure environment for everyday life has been identified as especially important for a person's overall wellbeing (Charmaz, 1995; Smith, 2012). When our lifeworld-home, place, local environment - operates without disruption, we are usually indifferent to it. However, Edelstein (2002) has noted that contamination affects people's 'normal' assumptions about life, particularly as they relate to health, personal control, home, and environment. In such ways, the perceived security and safety of a resident's lifeworld can be disrupted, diminishing its ability to accommodate 'human flourishing' (Fleuret and Atkinson, 2007, p.109) or ensure 'optimal psychological experience and functioning' (Deci and Ryan, 2008, p.1). Central to a resident's diminished wellbeing is deterioration of ontological security, which is 'the confidence that most human beings have in the continuity of their self-identity and in the 
constancy of their social and material environments' (Giddens, 1991, p.92). Ontological security is one's security of being-in-the-world, and provides grounding for one's sense of self and belonging, and, in turn, well-being (Fleuret and Atkinson, 2007).

While research suggests that worry can have a range of negative effects on a person's health and wellbeing, it is important to note that it can have a positive consequence. Like other forms of anticipatory cognition, worry can play a critical role in adaptive decision-making, with an appraisal of impending negative thought or danger allowing inner preparation for a subsequent threat or danger stimulus (Bechara et al., 1997; Peters et al., 2006; Tallis et al., 1994, p.62; Waters, 2008, p. 581). As MacGregor (1991, p.321) has suggested, 'we master or make controllable [risks] because we invest a great deal of worry in them'.

In this framework, a broad range of factors shape residents' levels of worry. The first of these factors relates to residents' socio-demographic characteristics, the next relates to their physical context, and the last to the contaminant types themselves. The attributes constituting each factor are outlined below. While these attributes are identified on the basis of existing research, the study reported here involved a mixed methodology to ascertain whether these or other attributes have a strong effect on residents' worries about the impact of contaminants from nearby source sites.

Socio-demographic characteristics: Research has increasingly recognized that the effects of environmental contamination on health are inequitably distributed, disproportionately affecting people on the basis of factors such as gender (Cutter, 1995; Mansfield, 2012; Sultana, 2009; 2012), socioeconomic status (Cotter and Patrick, 1981; Darley, 1994; Few and Tran, 2010), and vulnerability (Few and Tran, 2010). Furthermore, compared to the general population those living with a disability or chronic illness are more likely to experience negative health and diminished quality of life due to exposure to environmental hazards (Abbott and Porter, 2013; Kelman and Stough, 2015; Kovats and Kristie, 2006; Twigg et al., 2011). Whether this inequitable distribution extends to residents' worry about environmental contaminants remains unknown, although research into worry and related topics such as hazard anxiety suggest it might. Previous studies have revealed that socio-demographic factors - gender, age, socio-economic status - can determine an individual's worry about remediation of nearby contaminated sites (Prior et al., 2017), and other studies have found that similar factors affect human responses to environmental hazards other than contaminants (Ahmad et al., 2017; Ajibade and McBean, 2014; Blake et al., 2017). Furthermore, Gershon 
et al. (2016) have found that 'hazard anxiety' following exposure or increased awareness of hazards was more likely to be found amongst persons with disabilities or long-term illness. Influenced by these studies, our framework proposes that residents' levels of worry about contaminates from nearby source sites are not 'evenly' distributed across the population, and instead are influenced by their socio-demographic profiles and other personal characteristics.

Physical context: Studies have drawn attention to the role that sense of place plays in residents' perceptions of local contamination (Bickerstaff et al., 2006; Bickerstaff and Simmons, 2009), and have highlighted the point that perceived personal risk is related to proximity to environmental hazard sources (Lindell and Earle, 1983; Lindell and Hwang, 2008; Severtson and Burt, 2012; Signorino, 2012), suggesting that people generally believe their risk decreases with distance from a source site. Despite this $\mathrm{x}$, no studies have examined the ways in which residents' proximity to a contaminated site, or their sense of place, affects their levels of worry about the effects of any given contaminant associated with that site. In our framework 'sense of place' is understood as a broad construct that incorporates elements of both place identity (Simmons and Walker, 2004) and place attachment (Bonaiuto et al., 2002 p.636; Wakefield et al., 2001): the connections between local residents and immediate environs via personal and collective memories, histories, meanings, concerns, and local cultures. As opposed to knowledge about a place, sense of place forms over time (Tuan, 1991) through psychological investment and repeated encounters that gradually accumulate to provide a sense of self and belonging.

The impact of boundaries demarcating the contaminated and uncontaminated is a common theme in the geographical literature on contamination. These boundaries are both physical (Aiken and Leigh, 1975; Galt, 2008, 2010; Herod, 2011; Hinchliffe et al., 2013; Whittow, 1987) and psycho/social (Segrott and Doel, 2004; Crang and Zhang, 2012) and in some cases overlap (Mansfield, 2012). Discussions about borders extend from physical environmental boundaries (Hinchliffe et al., 2013) to human subjects, particularly vulnerable populations, who are imagined as boundaries between outside environmental contamination and populations (Mansfield, 2012). These physical and subjective boundaries are, in turn, represented on maps and plans (Galt, 2008). As Severtson and Vatovec (2012) have noted, images shape what people see in hazard contexts; for example, colours and lines on a map can have substantial impacts on how people see and believe. Influenced by these studies, our framework proposes that residents' levels of worry about contaminants from nearby source sites is affected by the physical and psycho/social boundaries they perceive and can be 
captured in representational maps demarcating the extent of the contaminant created by organisations involved in remediating contaminated sites.

Contaminant characteristics: Increasingly, studies have revealed that contamination is culturally and socially understood, encompassing people's beliefs and values (Aldred and Jungnickel, 2013; Dosman et al., 2001; Eiser et al., 2007; Freudenberg, 1997; Jewitt, 2011). An example illustrating this is Sultana's (2012) study of the social and cultural effects of arsenic as contaminant. Our framework proposes that residents' levels of worry about contaminants are influenced by the types of contamination associated with a nearby source site, the cultural and social stigma attached to those types of contaminant, and other characteristics of those types of contaminant, such as their visibility.

\section{Methodology}

Drawing from the framework described above, we have had the following research questions:

RQ1. What are the main factors that determine residents' levels of worry for contamination from nearby source sites?

$R Q 2$. What do residents worry about, and how do their worries about contamination from nearby source sites affect their wellbeing?

We have addressed those research questions using empirical insights collected in a telephone survey of 485 residents aged 18 years and older living near 13 contaminated sites in New South Wales, South Australia, the Australian Capital Territory, Tasmania, Queensland, and Victoria. Purposive sampling was used to select the sites. Suitable sites were identified through an extensive consultation process with the Australian remediation industry, state environmental protection agencies, and the Australian Land and Ground Water Association. Each site had a range of recognised environmental contaminants present: heavy metals (lead, cadmium, mercury, and arsenic), hydrocarbons (hydrocarbon compounds derived from petroleum sources, including petrol, diesel and kerosene and lubricating oils/greases), chlorinated solvents (chlorinated hydrocarbons used in dry cleaning), and waste (which can include liquids, solids, and gases), and asbestos. All sites included in the study were in urban areas and varied with regards to type and number of contaminants located at the site, and background of the site (e.g., age, and history of site). These ranged from small sites, such as 
petrol stations with short remediation timeframes (e.g., 3 months), through to large sites with multiple industrial uses spanning many decades where remediation will continue over many years.

Reflecting the methodological pluralism in health geographies research (Kearns and Gesler, 1998, p.612; Kearns and Moon, 2002; Kwan, 2012), the study addressed the research question using both a regression analysis of closed-format questions and a coding analysis of open-format questions from the survey. Closed-format questions alone were suboptimal for addressing the study's research question: given that there is little to no research examining the geography of residents' worry about contamination, it seemed unlikely that any survey would be capable of establishing in advance the full range of responses that might be given by residents (Irwin and Wynne, 1996; Nisbet and Scheufele, 2007). Hence, while the regression analysis of closed-format questions was designed to provide robust quantitative findings of likely dimensions of residents' geographies of worry, the coding analysis was used to provide a more heterogeneous understanding of those dimensions than the standard closed-format questions allowed (Sturgis and Allum, 2004).

To protect the confidentiality and anonymity of participants and sites, only generic information is provided in the remainder of this paper in accordance with the approval from The University of Technology Sydney Human Research Ethics Committee (Reference no. 2015000270).

\section{Survey measures and recruitment}

Participants were randomly selected from a residential telephone database for the neighbourhoods surrounding the 13 contaminates sites. The survey response rate was $19 \%$. A pilot of the survey was conducted with 50 participants randomly selected from the telephone database to refine the study's instruments. The final survey used computer-assisted telephone interviewing (CATI) software application, and was completed between 24 March 2014 and 30 September 2014 by 12 researchers calling residents on weekdays between 15:30 and 20:00. These researchers had both training and experience in conducting CATI, and were briefed on the content of the survey. If calls went unanswered or were diverted to voice-mail, up to five further attempts were made to contact each resident. Participants were asked their age at the outset of the survey to determine their eligibility (i.e., 18 years and over). 
Within the survey the participant was read a brief outline of a contaminant that had been found at a site near to their place of residence. The description provided to residents included: the type of contaminant (e.g., mercury), the location of the contaminant, how the contamination occurred, and how it behaved (e.g., groundwater). No potential consequences (e.g. health risks) related to the presence of the contaminant were described, to avoid influencing the responses to the survey. Given the vast range of contaminants within the environment, the study focused on five key types of contaminants within the Australian context including: heavy metals, hydrocarbons, chlorinated solvents, waste, and asbestos.

An 11-point Likert scale question was used to rate their degree of worry about the contaminant at the nearby site. Participants were asked 'how worried are you about the contamination at the [site], where 0 is not at all worried, and 10 is extremely worried?' This question was the dependent variable in the regression analysis.

Independent variables for the regression analysis were drawn from responses to survey questions that focused on the participants' socio-demographic characteristics (gender, age, income, educational attainment, and status as living with a long-term disability or with a chronic illness); physical context (proximity of contaminated site, sense of place); and views on types of contaminant (each of these is described in detail in Table 1). In particular, location data in the form of latitude and longitude coordinates for the home of each participant were also collected. Polygons were created for the boundaries of each contamination site using geographic information system (GIS) software. The minimum Cartesian distance (that is, the minimum distance between participant and contamination site boundary) was calculated between the participant's home and nearby site, and, in the regression analysis, was used as a measure of physical proximity between each participant and the contamination site.

\section{Table 1: Independent variables for the regression analysis}

\section{[Insert Table 1 here]}

Participants were also asked to provide an open-ended response to the question 'What is the first thought or image that comes to mind when you think of the [type] contamination at the [name of site]?' Open-ended responses to this question were used in the study's coding analysis.

\section{Participant characteristics}


Of the 485 participants in the study, 54 per cent $(n=269)$ of the participants were female, and 46 per cent $(n=216)$ were male. The age distribution was $18-89$ years. 7 per cent $(n=36)$ were under 35 years of aged, 31 per cent $(n=148)$ were aged $35-54$ years, 62 per cent $(n=301)$, and 9 per cent $(n=45)$ were aged 55 years or more. Most participants $(n=402,83 \%)$ reported that they did not live with a disability or long-term illness, compared to 16 per cent $(n=78)$ of participants who indicated that they did; five chose not to answer this question.

\section{Regression analysis}

Ordered logistic regression analysis was used to determine the influence of a range of sociodemographic, physical context, and contaminant-related characteristics on participants' levels of worry about contamination from nearby source sites (Table 1). Since the dependent variable (worry) was measured on a Likert scale, it was considered an ordinal variable. SPSS and $\mathrm{R}$ software were used to carry out the regression data processing and analysis. We sought correlated variables either by eliminating or combining duplicate or redundant variables (also discussed in Table 1).

\section{Coding Analysis}

Coding analysis of the open-ended question was used to elaborate on the determinants identified in the regression analysis and to provide insights into the impact of residents worry on their wellbeing. Two researchers coded the data manually, using SPSS to record frequencies of codes, and two cycles were used to identify those codes (Sandelowski et al., 2009; Sandelowski et al., 2012):

1. The 485 responses to the open-ended survey question were coded for 'worry' related content (Saldaña, 2013). Just over fifty per cent $(n=249)$ were coded as incorporating some reference to the substantive word 'worry+' or synonyms (for example, be worried, worrisome, daunting, perturbing, trying, taxing, troublesome, unsettling).

2. Elaborative coding and focused coding were then applied to the data. Elaborative coding involves analysing textual data in order to develop the findings of a previous study or stage of study further (Saldaña, 2013; Auerbach and Silverstein, 2003). Here, the aim was to enhance understanding of the findings from the regression analysis. Focused coding was also used to uncover frequently occurring themes on how residents' worry affected their wellbeing, and to identify the focus of their worry. 
Where verbatim responses are presented in the results section below, participants' basic details are represented in brackets after the verbatim response as follows: gender, age, and interview identification number (for example, female, 45, 2415). These verbatim responses from the coded text were selected based on their information richness.

\section{Results}

The findings from the regression analysis and coding analysis were combined to reveal the overlapping dimensions of the geography of residents' worries about contamination from nearby source sites. The first part of the results addresses the study's first research question by presenting findings on the most salient determinants of residents' levels of worry about contamination from a nearby site. These salient determinants include those identified as significant within the regression analysis (Table 2: the heterogeneity of worry within residential populations; residents' proximity to the site; contamination boundaries; and the worry effect of contaminant types). The second part of the results addresses the study's second research question, and considers how residents' worries about contamination affects their wellbeing in terms of perceived and experienced disruptions to health and wellbeing, including adverse effect on their ontological security.

Table 2: Ordered logistic regression determining the likelihood of worry about contamination

[Insert Table 2 here]

\section{Factors determining residents' levels of worry}

Socio-demographic characteristics: Participants' levels of worry for the contaminant were unevenly distributed based on a range of socio-demographic characteristics (Table 2). Gender had a significant association with worry, with females more likely to worry about contamination than males (OR $0.44 ; 95 \%$ CI $0.31,0.63 ; \mathrm{p}=0.000)$. There was no significant effect found between people on lower income and worry, although there was a significant difference amongst the higher income groups. Those with a moderately high income (AU $\$ 80,000$ to $\$ 120,000$ ) were significantly more likely to worry about contamination than people on a higher income (over $\$ 120,000$ ) (OR 1.77; 95\% CI 1.09, 2.88; $\mathrm{p}=0.021$ ). The ordinal logistic regression found that people who reported living with a disability or longterm illness were significantly more likely to worry about contamination compared to those 
that did not report living with a disability or long-term illness (OR 12.49; 95\% CI 7.58, 20.58; $\mathrm{p}=0.000)$.

Proximity of contaminated site: The ordinal logistic regression found that proximity of the contaminated site was a significant influence on participants worry; those who lived closer to a contaminated site were more likely to worry about contamination than those who lived further away (OR 1.36; 95\% CI 1.03, 1.80; $p=0.031$ ) (Table 2). This association between increased levels of worry and proximity to a contaminated site was reflected in participants worried about how adverse effects to health were amplified by proximity to the source site of the contamination (31 percent, 76 of 249). As participants noted: 'Very unsafe and unhealthy for people living close' (female, 40, 3220); 'Cancer problems that arise living close to the site' (female, 66, 3332); and 'The closer you live to it the more the chance of getting something' (female, 80,7001 ).

Boundaries: Participants explained that they had higher levels of worry about the perceived health risks of contamination in the nearby environment for certain socio-demographic groups compared to others. Pregnant women and children, were understood by participants, as being more likely than others to be vulnerable to the perceived health effects of contaminants (female 35, 7005). For participants, the vulnerability of pregnant women and children positioned them as a front line, and a human boundary between, the broader population and the health risks associated with the contaminant. For example, as one participant noted: 'There may just be a little bit of contamination, but a little builds up and then you pass that onto your [unborn] children.' (female, 75, 7009).

The levels of worry that participants had in relation to the possible impact of a contaminant on the health and wellbeing of residents at six of the 13 sites correlated with the presence of exclusion zones put in place around contaminated sites by state and territory environment protection authorities and then mapped. For participants living near the sites, exclusion zones established observable boundaries that amplified worry about disruptions to health and wellbeing in given zones and reduced worry outside zones, including in relation to community and property values.

Contaminant characteristics: Three contaminant types were found to significantly influence worry; the presence of hydrocarbon, metal, and chlorinated solvent was more likely to cause worry about contamination than asbestos (Table 2). Higher levels of worry associated with hydrocarbon, metal and chlorinated solvents resulted from their invisibility and the 
uncertainty this generated for participants about the presence of these contaminants. As one participant explained, a contaminants invisibility, 'raises worry...you're never going to know if it's treated property because - have you got it all, how will we know.... Whereas [if its] visible, you can pick it up and take it away and put it in a cell and you know all of that's gone' (female, 55, 7002). Asbestos was associated with lower levels of worry, which participants explained was because greater media attention and public health awareness raising campaigns focusing on asbestos resulted in people feeling more confident in knowing what to do in the event of asbestos contamination. As one participant explained:

There was a whole lot of stuff on the media about that asbestos. People were concerned about asbestos, you know, old buildings. But...people are much more aware [of asbestos] these days. I think, at least we know how to handle that now. You know that if you find asbestos in your home, that you call someone....People are much more educated these days. (female, 45, 7003).

\section{The focus and experience of residents' worry}

Participants' worries were strongly focused on how contamination from nearby source sites might disrupt their own health and wellbeing, and that of other residents $(63 \%, 156$ of 249). This worry focused on contaminants' perceived potential to amplify incidents of mortality and morbidity, for example, 'cancer' or 'lung disease' (female, 58, 3273; female, 68, 3379; female, 63, 266), and increased levels of general 'illness' or 'sickness' in residents (male, 57, 76 ; male, 74, 2066). One focus of these worries was the possibility of cognitive impairment of infants and children (male, 70, 400; female, 65, 296). Moving beyond concerns for physical health, residents also held considerable worries about the psychological and lifestyle impacts of contamination $(51 \%, 126$ of 249$)$.

Participants also worried about the ways in which contaminants amplified incidents of mortality and disease in flora, fauna, fungi, and bacteria (41\%, 103 of 249). As participants noted: 'I'm worried about [the contaminant] endangering the life of the people and nature ... the health of people, plants and animals' (male, 74, 3177), and '[I am worried about] all the dead fish and the damage to the surrounding parks' (female, 83, 226).

Participants worried about the threat that contaminants posed to the security of their homes $(53 \%, 116$ of 249$)$. Home in this context refers to the place, including both house and surrounding local environment, where participants lived. Participants' worries focused on 
how positive associations of 'home' with privacy, protection, security, amenity, and selfidentity, were destabilised and inverted by the presence of the contamination. Participants reported that awareness of the presence of a contaminant replaced these positive associations with negative ones; 'home' becomes a conceivably hostile environment, filled with 'lurking' danger (male, 55, 4026).

Household services came to the fore of the participants' worries as sources of uncertain health risks, including, for example water supply or the soil found in situ in yards (female, 64, 5045; female, 62, 386). Concern about these uncertain health risks were amplified by the fact that contaminants were often perceived by participants as 'invisible', 'dangerous', and 'uncontrollable' home intruders (female, 61, 8; female, 70, 25; male, 58, 2268). As one participant asserted, 'I'm worried ... the fact that [the contaminant] can come up through the soil and leach into the water table and the air ... make its way into my home ... I feel exposed, unsafe, in danger' (female, 71, 4045).

Furthermore, participants shared with us how their worry had the potential to affect how they used their homes and local environments. As one noted, contamination had the potential to affect 'the places that allowed me to live a happy and healthy life ... turning them into places to worry about, to fear ... transforming them from places of safety to dangerous places' (male, 37, 412). Another said, 'We heard about contamination in the area close to a local school and all the parents were taking their kids out of school because they were so afraid of contaminants' (male, 75, 7003).

The participants also noted how the health risks posed by contaminants' presence threatened the 'home' as a source of financial security, threatening the longer-term wellbeing of residents. As one participant noted, 'People's properties may be devalued due to contamination ... it makes me anxious' (female, 69, 2021).

As can be seen from the commentary above, worry was often manifested by residents, through both curtailing the activities of their everyday life, and through worry being linked to potentially debilitating psychological states such as anxiety. As another participant noted:

'Miss it being a great place to walk the dogs' (female, 55, 3167).

Furthermore, some participants $(13 \%, 32$ of 249$)$ indicated that their worry about contamination was accompanied by negative, debilitating feelings of fear, tiredness, exhaustion, unhappiness, despondency, violation, and exposure. For some, this was 
connected with possible bodily contamination. One participant stated, 'Poisons in the air and the food we eat. ... It worries me, I feel exposed and frightened. I'm tired and exhausted from it all' (female, 69, 2186). Another said, 'It makes you feel uneasy when you think it is at a site where people are living it might get into the drinking water ...it scares me' (female, 76, 4176). Others felt a loss of agency; for instance: 'The little creek down at [Road name] Road, I am worried about that. ...But what can I do?' (male, 47, 79) One participant asserted the contamination was 'dangerous [and] causes insanity' (female, 57, 5264), and another said, 'I feel sad for the dwellers nearby' (female, 65, 2150).

Few participants $(6 \%, 15$ out of 249$)$ referred to the ways in which worry about contamination could have a positive effect, motivating or stimulating them to develop an increased awareness of the effects of the contamination, and helping them to clarify their thoughts and feelings. One participant stated, 'I'm fairly confident the technology they have will help. I allayed my worries by calling the [company] and looking stuff up on the internet' (female, 78, 5539). Others took action to find information. One said, 'I was worried about it, so I went to the community info day, and found out about it. ... It's a shame that it ever happened but they seem to be doing a good job of cleaning it up' (female, 84, 3106). Another asserted that ' $[\mathrm{t}]$ he [company] didn't help ... I tackled my worries by calling the [environment agency]. ... Confident it will be disposed of in the right way' (female, 54, 3062)

\section{Concluding discussion}

This paper developed a geography of residents' worries about the effects of the presence of contaminants in nearby source sites on their own and others' health and wellbeing. The insights derived from a survey of residents around Australia drew attention to how their levels of worry are determined by socio-demographic characteristics and physical contexts, as well as by the contaminants' characteristics. The survey also provided insights into the health and wellbeing concerns manifest in the residents' worries, and how such worries adversely affect their wellbeing. In concluding this paper, we discuss these insights in the context of broader research, and finish by highlighting the study's limitations and opportunities for further research.

The levels of worry reported among participants vary according to socio-demographic characteristics, a finding which supports our foundational premise. In this study, women were more likely to worry about contamination in their residential area than men. This aligns with 
research which has found that women are more likely to report being concerned about the environment (McCright and Xiao, 2014), and may be more likely to experience anxiety disorders in which "worry" is reported as a core feature (McLean et al., 2011). Those in highest income brackets $(\$ 80-\$ 120 \mathrm{k})$ were found to be more likely to worry about contamination, which aligns with remediation technology research that found residents with a higher income (\$80-\$120k) were more likely to worry than others (Prior et al., 2017). The increased levels of worry reported by those living with disability or long-term illness suggest that disability or long-term illness should be considered in addition to other sociodemographic variables such as gender by professionals involved in the development of community engagement strategies associated with the risk management and remediation of contaminated sites (Holifield, 2012; Mansfield, 2012).

Unsurprisingly, our study found that people who lived in close proximity to a contaminated site were more likely to worry about contamination than those who lived further away. This finding about the relationship between worry and proximity aligns with previous studies, which suggest that people generally believe their risk from an environmental hazard source decreases with distance from the hazard (Lindell and Earle, 1983; Lindell and Hwang, 2008). This point is particularly important in broader studies that use proximity or distance to hazardous releases as a proxy for potential exposure to harm (Brender et al., 2011; Chakraborty et al., 2011; Margai, 2001; Pollock and Vittas, 1995; Stretesky and Lynch, 1999).

In this study, sense of place was not a significant determinant of worry, although we note findings from a previous study reporting that people with a sense of belonging to their community are more likely to worry about contamination remediation technologies (Prior et al., 2017). More work is likely warranted on this aspect of the problem under investigation.

We also found that physical and psycho-social boundaries and mapped zones amplified residents' worries, and exacerbate concerns about possible stigmatisation or financial or other penalty (Fleuret and Atkinson, 2007). Vulnerable populations, such as pregnant women and children, were found to be a focus of worry for residents, given that they are perceived as human boundaries for health risk associated with contamination. This finding about vulnerable populations aligns with research by Mansfield (2012), who highlights how risk spatialises reproductive women as the 'bodily threshold between the contaminated environment and the population' (p. 969). Exclusion maps of the spread of contamination 
from a source site were found to mediate residents' levels of worry about health risks, in line with other research which has found that risk communication image features may influence emotions (Dransch et al., 2010; Severtson and Vatovec, 2012), and that these featuresshading or boundary - can have substantial impacts on what participants see and believe (Severtson and Vatovec, 2012). More broadly, the findings align with research on contamination that acknowledges the existence of 'stigma' with respect to real estate and property rights (Mundy, 1992; Patchin, 1988; Patchin, 1991; Patchin, 1994; Rinaldi, 1991; Wiltshaw, 1998).

Finally, the study found that residents were more likely to worry about hydrocarbon, metal, or solvent, because they were invisible and less well known, and less worried about asbestos because it is visible and known. These insights about factors that amplify worry for contaminant types align with broader research, which has found that invisible and less well known types of contaminants are more likely to be associated with higher levels of concern and uncertainty amongst members of the public than other forms of contamination, regardless of actual health risk (Dosman et al,. 2001; Eiser et al., 2007; Freudenberg, 1997).

Beyond considering the factors that determine residents' levels of worry about contamination, this study provided insights into how health and wellbeing manifested within residents worry for contaminants. Residents' worries were strongly focused on how environmental contaminants might disrupt their physical and mental health, and lifestyle, and less focused on how the contaminant might affect the health of flora, fauna, and the broader ecosystem. This hierarchy of focus mirrors that found in recent research into residents' worries about the application of remediation technologies to nearby source sites (Prior et al., 2017).

Furthermore, the study provided insights into how worry about contaminants from nearby source sites adversely affects the health and wellbeing of residents. These insights reflect broader research that highlights that higher levels of worry have been linked to a range of direct and indirect negative health and quality of life impacts (Andrea et al., 2004; Brosschot et al., 2006; Keyes and Simoes, 2012). Findings revealed that as a site of ontological security, the home is adversely affected by contamination, with positive feelings of personal and place-based control being supplanted by a sense of being threatened, and feeling insecurity and doubt. This new uncertainty and danger reduces people's ability to flourish and function and increases worry and the fear of engaging in everyday activities that can lead to bodily 
contamination. Furthermore, this uncertainty and danger can lead to a perceived lack of control over one's place or location and create feelings of helplessness, which may lead to psychological distress (Evans, 2003). These findings about the impact of contamination on home align with arguments within critical geographies of home, which point to how positive connotations of home are constructed, and can be subverted by negative experiences (Blunt and Dowling, 2006). Home is an unstable site with shifting meanings, and residents' worry about the effects of contamination highlights this instability.

Despite the diverse negative effects on residents, we found that worry for contamination can also prompt coping strategies and problem-solving, reinforcing broader worry research (Davey, 1994; McGregor, 1991).

While this study provides a cornerstone for understanding the factors that constitute a geography of residents' worries about contamination from nearby source sites, it has limitations. First, findings may be generalizable to the Australian population but not so beyond that context. Second, the open-ended questions within the survey only elicited short verbatim responses, containing just a few words; this constrained our attempt to uncover worry narrative structures. Third, in addition to the potential for closed-format questions to shape or steer responses in a direction, a further consideration is that even when people have little or no understanding of the science they are being asked to evaluate, many will select one of the fixed alternatives offered to them rather than admit ignorance, simply because the formalities and conventions of surveys stipulate possible answers (Sturgis and Smith, 2010).

Future studies may explore relationships between residents' worries, contaminated environments, and long-term health-related outcomes. The impact on mental health and wellbeing of long-term worry about contamination is currently unknown; more research could seek to determine such longitudinal effects of worry on those living close to contamination sites, and to ascertain the impact of such concern on their quality of life. Such research might focus on both the adverse effects of worry and the potential for worry to generate coping and problem-solving strategies (McGregor, 1991).

\section{References}

Abbott, D. and Porter, S., 2013. Environmental hazard and disabled people: From vulnerable to expert to interconnected. Disability and Society, 48(6), pp.839-852. 
Ahmad, J. Morshed-Ahmad, M. Sadia, H. and Al, E., 2017. Using selected global health indicators to assess public health status of population displaced by natural and manmade disasters. International Journal of Disaster Risk Reduction, 22, pp.228-237.

Aiken, S.R. and Leigh, C.H., 1975. Malaysia's emerging conurbation. Annals of the Association of American Geographers, 65(4), pp.546-563.

Ajibade, I. and Mcbean, G., 2014. Climate extremes and housing rights: A political ecology of impacts, early warning and adaptation constraints in lagos slum communities. Geoforum, 55, pp.76-86.

Aldred, R. and Jungnickel, K., 2013. Matter in or out of place? Bicycle parking strategies and their effects on people, practices and places. Social \& Cultural Geography, 14(6), pp.604-624.

Andrea, H. Beurskens, A.J.H.M. Kant, I.J. Davey, G.C.L. Field, A.P. and Van Schayck, C.P., 2004. The relation between pathological worrying and fatigue in a working population. Journal of Psychosomatic Research, 57(4), pp.399-407.

Auerbach, C.F. and Silverstein, L.B., 2003. Qualitative data: an introduction to coding and analysis, New York: New York University Press.

Bechara, A. Damasio, H. Tranel, D. and Damasio, A.R., 1997. Deciding Advantageously Before Knowing the Advantageous Strategy. Science, 275(5304), pp.1293-1295.

Bickerstaff, K. and Simmons, P., 2009. Absencing/presencing risk: Rethinking proximity and the experience of living with major technological hazards. Geoforum, 40(5), pp.864872.

Bickerstaff, K. Simmons, P. and Pidgeon, N., 2006. Situating local experience of risk: Peripherality, marginality and place identity in the UK foot and mouth disease crisis. Geoforum, 37(5), pp.844-858.

Bickerstaff, K. and Walker, G., 2003. The place(s) of matter: matter out of place - public understandings of air pollution. Progress in Human Geography, 27(1), pp.45-67.

Blake, D. Marlowe, J. and Johnston, D., 2017. Get prepared: Discourse for the privileged? International Journal of Disaster Risk Reduction, 25, pp.283-288.

Blunt, A. and Dowling, R., 2006. Hoe. London: Routledge.

Bonaiuto, M. Carrus, G. Martorella, H. and Bonnes, M., 2002. Local identity processes and environmental attitudes in land use changes: The case of natural protected areas. Journal of Economic Psychology, 23(5), pp.631-653. 
Borkovec, T.D., 1994. The nature, functions, and origins of worry. In G. Davey and F. Tallis, eds. Worrying: Perspectives on theory, assessment, and treatment. New York: Wiley. pp.5-34.

Borkovec, T.D. Robinson, E. Pruzinsky, T. and Depree, J.A., 1983. Preliminary exploration of worry: Some characteristics and processes. Behaviour Research and Therapy, 21(1), pp.9-16.

Brender, J.D. Maantay, J.A. and Chakraborty, J., 2011. Residential Proximity to Environmental Hazards and Adverse Health Outcomes. American Journal of Public Health, 101(Suppl 1), S37-S52.

Brosschot, J.F. Gerin, W. and Thayer, J.F., 2006. The perseverative cognition hypothesis: A review of worry, prolonged stress-related physiological activation, and health. Journal of Psychosomatic Research, 60(2), pp.113-124.

Carbonell, R., 2013. Toxic waste threatens over 150,000 Australian sites, from http://www.abc.net.au/news/2013-09-16/toxic-waste-threatens-1502c000-australiansites/4960618.

Chakraborty, J. Maantay, J.A. and Brender, J.D., 2011. Disproportionate Proximity to Environmental Health Hazards: Methods, Models, and Measurement. American Journal of Public Health, 101(Suppl 1), S27-S36.

Charmaz, K., 1995. The body, identity and self. Sociological Quarterly, 36(4), pp.657-680.

Cotter, J.V. and Patrick, L.L., 1981. Disease and ethnicity in an urban environment. Annals of the Association of American Geographers, 71(1), pp.40-49.

Crang, M. and Zhang, J., 2012. Transient dwelling: trains as places of identification for the floating population of China. Social \& Cultural Geography, 13(8), pp.895-914.

Cutter, S.L., 1995. The forgotten casualties: women, children, and environmental change. Global Environmental Change, 5(3), pp.181-194.

Darley, S., 1994. But the working class don't care about the environment ... do they? Social Alternatives, 13(2), pp.37-41.

Davey, G., 1994. Pathological worry as exacerbated problem solving. In G. Davey and F. Tallis, eds. Worrying: Perspectives on theory, assessment, and treatment. New York, NY, Wiley. pp.35-59.

Davis, J.S., 2005. Representing Place: "Deserted Isles" and the Reproduction of Bikini Atoll. Annals of the Association of American Geographers, 95(3), pp.607-625.

Deci, E.L. and Ryan, R.M., 2008. Hedonia, eudaimonia, and well-being: an introduction. 
Dosman D.M. Adamowicz W.L. \& Hrudey S.E., 2001. Socioeconomic determinants of health and food safety-related risk perceptions. Risk Analysis, 21(2), pp.307-317.

Dransch, D. Rotzoll, H. and Poser, K., 2010. The contribution of maps to the challenges of risk communication to the public. International Journal of Digital Earth, 3(3), pp.292-311.

Eakin, H. Lerner, A.M. and Murtinho, F., 2010. Adaptive capacity in evolving peri-urban spaces: Responses to flood risk in the Upper Lerma River Valley, Mexico. Global Environmental Change, 20, pp.14-22.

Edelstein, M.R., 2002. Contamination: The Invisible Built Environment. In R.B. Bechtel and A. Ts'erts'man, eds. Handbook of Environmental Psychology. New York: Wiley, J. pp.559-588.

Eiser, J.R. Stafford, T. Henneberry, J. and Catney, P., 2007. Risk perception and trust in the context of urban brownfields, Environmental Hazards. Human and Policy Dimensions, 7(2), pp.150-156.

Escamilla, V. Knappett, P.S.K. Yunus, M. Streatfield, P.K. and Emch, M., 2013. Influence of Latrine Proximity and Type on Tubewell Water Quality and Diarrheal Disease in Bangladesh. Annals of the Association of American Geographers, 103(2), pp.299308.

European Environment Agency, 2014. Progress in Management of Contaminated Sites.

Evans, G.W., 2003. The built environment and mental health. Journal of Urban Health: Bulletin of the New York Academy of Medicine, 80(4), pp.536-555.

Ferrer, R.A. Portnoy, D.B. and Klein, W.M.P., 2012. Worry and Risk Perceptions as Independent and Interacting Predictors of Health Protective Behaviors. Journal of Health Communication, 18(4), pp.397-409.

Few, R. and Tran, P.G., 2010. Climatic hazards, health risk and response in Vietnam: Case studies on social dimensions of vulnerability. Global Environmental Change, 20(3), pp.529-538.

Fleuret, S. and Atkinson, S., 2007. Wellbeing, health and geography: A critical review and research agenda. New Zealand Geographer, 63(2), pp.106-118.

Flörke, M. Kynast, E. Bärlund, I. Eisner, S. Wimmer, F. and Alcamo, J., 2013. Domestic and industrial water uses of the past 60 years as a mirror of socio-economic development: A global simulation study. Global Environmental Change, 23(1), pp.144-156.

Freudenburg, W.R., 1997. Contamination, Corrosion and the Social Order: An Overview. Current Sociology 45(3), pp.19-39. 
Galt, R.E., 2008. Beyond the circle of poison: Significant shifts in the global pesticide complex, 1976-2008. Global Environmental Change, 18(4), pp.786-799.

Galt, R.E., 2010. Scaling Up Political Ecology: The Case of Illegal Pesticides on Fresh Vegetables Imported into the United States, 1996-2006. Annals of the Association of American Geographers, 100(2), pp.327-355.

Gershon, R.R. Portacolone, E. Nwankwo, E.M. and Al, E., 2016. Psychosocial influences on disaster preparedness in San Francisco recipients of home care. Journal of Urban Health, 94(5), pp.606-618.

Giddens, A., 1991. Modernity and Self-Identity: Self and Society in the Late Modern Age. Cambridge: Polity Press.

Herod, A., 2011. What does the 2011 Japanese tsunami tell us about the nature of the global economy? Social \& Cultural Geography, 12(8), pp.829-837.

Hinchliffe, S., 2001. Indeterminacy in-decisions - science, policy and politics in the BSE (Bovine Spongiform Encephalopathy) crisis. Transactions of the Institute of British Geographers, 26(2), pp.182-204.

Hinchliffe, S. Allen, J. Lavau, S. Bingham, N. and Carter, S., 2013. Biosecurity and the topologies of infected life: from borderlines to borderlands. Transactions of the Institute of British Geographers, 38(4), pp.531-543.

Hirsch, C.R. and Mathews, A., 2012. A cognitive model of pathological worry. Behaviour Research and Therapy, 50(10), pp.636-646.

Holifield, R., 2012. Environmental Justice as Recognition and Participation in Risk Assessment: Negotiating and Translating Health Risk at a Superfund Site in Indian Country. Annals of the Association of American Geographers, 102(3), pp.591-613.

Hou, D. and Li, F., 2017. Complexities Surrounding China's Soil Action Plan. Land Degradation \& Development, 28(7), pp.2315-2320.

Irwin, A. and Wynne, B., 1996. Introduction. In A. Irwin and B. Wynne, eds. Misunderstanding Science? Cambridge, Cambridge University Press

Jewitt, S., 2011. Geographies of shit: Spatial and temporal variations in attitudes towards human waste. Progress in Human Geography, 35(5), pp.608-626.

Kearns, R.A. and Gesler, W.M. 1998. Putting Health into Place: landscape, identity and well-being, Syracuse: Syracuse University Press

Kearns, R. and Moon, G., 2002. From medical to health geography: novelty, place and theory after a decade of change. Progress in Human Geography, 26(5), pp.605-625. 
Kelman, I. and Stough, L., 2015. Disabilities and Disaster: Explorations and Exchanges, New York: Palgrave-MacMillan.

Keyes, C.L. and Simoes, E.J., 2012. To flourish or not: Positive mental health and all-cause mortality. American Journal of Public Health, 102(11), pp.2164-2172.

Kovats, R.S. and Kristie, L.E., 2006. Heatwaves and public health in Europe. European Journal of Public Health, 16(6), pp.592-599.

Kwan, M.-P., 2012. Geographies of Health. Annals of the Association of American Geographers, 102(5), pp.891-892.

Landrigan, P.J. Fuller, R. Acosta, N.J.R. Adeyi, O. Arnold, R. Basu, N. Baldé, A.B. Bertollini, R. Bose-O'reilly, S. Boufford, J.I. Breysse, P.N. Chiles, T. Mahidol, C. Coll-Seck, A.M. Cropper, M.L. Fobil, J. Fuster, V. Greenstone, M. Haines, A. Hanrahan, D. Hunter, D. Khare, M. Krupnick, A. Lanphear, B. Lohani, B. Martin, K. Mathiasen, K.V. Mcteer, M.A. Murray, C.J.L. Ndahimananjara, J.D. Perera, F. Potočnik, J. Preker, A.S. Ramesh, J. Rockström, J. Salinas, C. Samson, L.D. Sandilya, K. Sly, P.D. Smith, K.R. Steiner, A. Stewart, R.B. Suk, W.A. Van Schayck, O.C.P. Yadama, G.N. Yumkella, K. and Zhong, M., 2018. The Lancet Commission on pollution and health. The Lancet, 391(10119), pp. 462-512.

Landrigan, P.J. Fuller, R. and Horton, R., 2015. Environmental pollution, health, and development: a Lancet-Global Alliance on Health and Pollution-Icahn School of Medicine at Mount Sinai Commission. The Lancet, 386(10002), pp.1429-1431.

Lindell, M.K. and Earle, T.C., 1983. How Close Is Close Enough: Public Perceptions of the Risks of Industrial Facilities. Risk Analysis, 3(4), pp.245-253.

Lindell, M.K. and Hwang, S.N., 2008. Households' Perceived Personal Risk and Responses in a Multihazard Environment. Risk Analysis, 28(2), pp.539-556.

Loyd, J.M., 2009. “A Microscopic Insurgent”: Militarization, Health, and Critical Geographies of Violence. Annals of the Association of American Geographers, 99(5), pp.863-873.

Malpas, J., 1999. Place and experience : a philosophical topography, Cambridge; New York: Cambridge University Press.

Mansfield, B., 2012. Environmental Health as Biosecurity: "Seafood Choices," Risk, and the Pregnant Woman as Threshold. Annals of the Association of American Geographers, 102(5), pp.969-976. 
Margai, F., 2001. Health risks and environmental inequity: A geographical analysis of accidental releases of hazardous materials. The Professional Geographer, 53(3), pp.422-434.

Mccright, A.M. and Xiao, C., 2014. Gender and environmental concern: Insights from recent work and for future research. Society \& Natural Resources, 27(10), pp.1109-1113.

Mcgregor, D., 1991. Worry of Technological Activities and Life Concerns. Risk Analysis, 11(2), pp.315-324.

Mclean, C.P. Asnaani, A. Litz, B.T. and Hofmann, S.G., 2011. Gender differences in anxiety disorders: Prevalence, course of illness, comorbidity and burden of illness. Journal of psychiatric research, 45(8), pp.1027-1035.

Mcqueen, A. Vernon, S.W. Meissner, H.I. and Rakowski, W., 2008. Risk Perceptions and Worry About Cancer: Does Gender Make a Difference? Journal of Health Communication, 13(1), pp.56-79.

Meade, M., 1976. Land development and human health in West Malaysia. Annals of the Association of American Geographers, 66(3), pp.428-439.

Mundy, B., 1992. Stigma and value. The Appraisal Journal, 60(1), pp.7-13.

Nisbet, M.C. and Scheufele, D.A., 2007. The Future of Public Engagement. The Scientist, 21, pp.38-44.

Patchin, P., 1988. Valuation of contaminated properties. The Appraisal Journal, 56(1), pp.716.

Patchin, P., 1991. Contaminated properties - stigma revisited. The Appraisal Journal, 59(2), pp.167-172.

Patchin, P., 1994. Contaminated properties and the sales comparison approach. The Appraisal Journal, 62(3), pp.402-409.

Peters, E. Slovic, P. Hibbard, J.H. and Tusler, M., 2006. Why worry? Worry, risk perceptions, and willingness to act to reduce medical errors. Health Psychology, 25(2), pp.144-152.

Pollock, P. and Vittas, M., 1995. Who bears the burden of environmental pollution? Race, ethnicity, and environmental equity in Florida. Social Science Quarterly, 76(2), pp.294-310.

Prior, J. Hubbard, P. and Rai, T., 2017. Using residents' worries about technology as a way of resolving environmental remediation dilemmas. Science of The Total Environment, 580, pp.882-899. 
Rinaldi, A., 1991. Comtainated properties: Valuation solutions. The Appraisal Journal, 59(3), pp.377-381.

Saldaña, J., 2013. The coding manual for qualitative researchers, Los Angeles: SAGE.

Sandelowski, M. Voils, C.I. and Knafl, G., 2009. On Quantitizing. Journal of Mixed Methods Research, 3(3), pp.208-222.

Sandelowski, M. Voils, C.I. Leeman, J. and Crandell, J.L., 2012. Mapping the Mixed Methods-Mixed Research Synthesis Terrain. Journal of Mixed Methods Research, 6(4), pp.317-331.

Scott, C.A. Robbins, P.F. and Comrie, A.C., 2012. The Mutual Conditioning of Humans and Pathogens: Implications for Integrative Geographical Scholarship. Annals of the Association of American Geographers, 102(5), pp.977-985.

Segrott, J. and Doel, M.A., 2004. Disturbing geography: obsessive-compulsive disorder as spatial practice. Social \& Cultural Geography, 5(4), pp.597-614.

Severtson, D.J. and Burt, J.E., 2012. The Influence of Mapped Hazards on Risk Beliefs: A Proximity-Based Modeling Approach. Risk Analysis, 32(2), pp.259-280.

Severtson, D.J. and Vatovec, C., 2012. The Theory-Based Influence of Map Features on Risk Beliefs: Self-Reports of What Is Seen and Understood for Maps Depicting an Environmental Health Hazard. Journal of Health Communication, 17(7), pp.836-856.

Signorino, G., 2012. Proximity and risk perception. Comparing risk perception 'profiles' in two petrochemical areas of Sicily (Augusta and Milazzo). Journal of Risk Research, 15(10), pp.1223-1243.

Simmons, P. and Walker, G., 2004. Living with technological rsik: industrial encroachment on sense of place. In A. Boholm and R. Lofsted, eds. Facility siting: Risk, power and identity in land use planning. London: Earthscan, pp.90-106.

Smallman-Raynor, M. and Cliff, A.D., 2008. The Geographical Spread of Avian Influenza A (H5N1): Panzootic Transmission (December 2003-May 2006), Pandemic Potential, and Implications. Annals of the Association of American Geographers, 98(3), pp.553582.

Smith, N., 2012. Embodying brainstorms: the experiential geographies of living with epilepsy. Social \& Cultural Geography, 13(4), pp.339-359

Stefanovic, I., 2008. Holistic paradigms of health and place. In J. Eyles and A. Williams, eds. Sense of place, Health and quality of life. Franham, UK: Ashgate. 
Stretesky, P. and Lynch, M., 1999. Environmental justice and the predictions of distance to accidental releases in Hillsborough County, Florida. Social Science Quarterly, 80(4), pp.830-846.

Sturgis, P. and Allum, N., 2004. Science in Society: Re-Evaluating the Deficit Model of Public Attitudes. Public Understanding of Science, 13(1), pp.55-74.

Sturgis, P. and Smith, P., 2010. Assessing the Validity of Generalized Trust Questions: What Kind of Trust are we Measuring? International Journal of Public Opinion Research, 22(1), pp.74-92.

Sultana, F., 2009. Community and participation in water resources management: gendering and naturing development debates from Bangladesh. Transactions of the Institute of British Geographers, 34(3), pp.346-363.

Sultana, F., 2012. Producing Contaminated Citizens: Toward a Nature-Society Geography of Health and Well-Being. Annals of the Association of American Geographers, 102(5), pp.1165-1172.

Tallis, F. Davey, G.C.L. and Capuzzo, N., 1994. The phenomenology of non-pathological worry: a preliminary investigation. In G. Davey and F. Tallis, eds. Worrying: Perspectives on theory, assessment, and treatment. New Your, NY: Wiley, pp.61-90.

Tuan, Y.-F., 1991. Language and the Making of Place: A Narrative-Descriptive Approach. Annals of the Association of American Geographers, 81(4), pp.684-696.

Twigg, J. Kett, M. Bottomley, H. and Al, E., 2011. Disability and public shelter in emergencies. Environmental Hazards, 10(3-4), pp.248-261.

United States Environment Protection Agency, 2016. Superfund Community Involvement Handbook.

Wakefield, S.E.L. Elliott, S.J. Cole, D.C. and Eyles, J.D., 2001. Environmental risk and (re)action: air quality, health, and civic involvement in an urban industrial neighbourhood. Health \& Place, 7(3), pp.163-177.

Waters, E.A., 2008. Feeling good, feeling bad, and feeling at-risk: a review of incidental affect's influence on likelihood estimates of health hazards and life events. Journal of Risk Research, 11(5), pp.569-595.

Whittow, J., 1987. Environmental Problems. Progress in Human Geography, 11(3), pp.417424.

Wiltshaw, D.G., 1998. Stigma, perception and the remediation of contaminated land. Journal of Property Research, 15(4), pp.285-303. 
Xu, B. Gong, P. Seto, E. Liang, S. Yang, C. Wen, S. Qiu, D. Gu, X. and Spear, R., 2006. A Spatial-Temporal Model for Assessing the Effects of Intervillage Connectivity in Schistosomiasis Transmission. Annals of the Association of American Geographers, 96(1), pp.31-46. 
Table 1: Independent variables for the regression analysis

\section{Socio-demographic characteristic}

University education: 0/1 dummy if the participant had a university degree.

Gender: 0/1 dummy if the participant is male.

Age under 35: 0/1 dummy if the participant is under 35 .

Age 35-54: 0/1 dummy for participants aged 25-54.

Age 55+: 0/1 dummy for participants aged 55+.

Income unspecified: 0/1 dummy for participants who did not specify income.

Income 0 to 40k: 0/1 dummy for household income between $\$ 0-\$ 40 \mathrm{k}$ p.a.

Income 40k to 80k: 0/1 dummy for household income between $\$ 40-\$ 80 \mathrm{k}$ p.a.

Income 80k to 120k: 0/1 dummy for household income between $\$ 80-\$ 120 \mathrm{k}$ p.a.

Income 120k+: 0/1 dummy for household income over \$120k p.a.

Disability/Long term Illness status: 0/1 dummy if disability/long term illness status was yes.

\section{Physical Context}

Proximity to contaminated site: The minimum Cartesian distance (that is, the minimum distance between participant and contamination site boundary) was used as a measure of physical distance between each participant and the contamination site.

Sense of place: combined response to the statements "I feel like I belong to the community where I live" \& "For me, this is the ideal place to live", which were found to be highly (0.87) correlated.

\section{Contamination type}

Hydrocarbon: 0/1 dummy if the contaminant discussed with the participant was classified as a hydrocarbon.

Heavy Metal: 0/1 dummy if the contaminant discussed with the participant was classified as a metal.

Chlorinated Solvent: 0/1 dummy if the contaminant discussed with the participant was classified as a solvent.

Waste: 0/1 dummy if the contaminant discussed with the participant was classified as a waste.

Asbestos: 0/1 dummy if the contaminant discussed with the participant was classified as asbestos. 
Table 2: Ordered logistic regression determining the likelihood of worry about contamination

\begin{tabular}{|c|c|c|c|c|c|}
\hline Coefficient & SE & $\mathrm{t}$ value & OR & OR 95\% & $\mathrm{p}$ value \\
\hline estimate & & & & CI & \\
\hline
\end{tabular}

\begin{tabular}{|c|c|c|c|c|c|c|}
\hline \multicolumn{7}{|l|}{ Age } \\
\hline $55+$ & 0.05 & 0.203 & 0.245 & 1.05 & $0.71,1.56$ & 0.806 \\
\hline Under 35 & 0.147 & 0.341 & 0.431 & 1.16 & $0.59,2.26$ & 0.666 \\
\hline Gender male & -0.815 & 0.178 & -4.577 & 0.44 & $0.31,0.63$ & $0.000 *$ \\
\hline \multicolumn{7}{|l|}{ Income } \\
\hline Zero to $40 \mathrm{k}$ & 0.328 & 0.304 & 1.077 & 1.39 & $0.76,2.52$ & 0.282 \\
\hline $40 \mathrm{k}$ to $80 \mathrm{k}$ & 0.183 & 0.247 & 0.740 & 1.20 & $0.74,1.95$ & 0.459 \\
\hline $80 \mathrm{k}$ to $120 \mathrm{k}$ & 0.572 & 0.248 & 2.304 & 1.77 & $1.09,2.88$ & $0.021 *$ \\
\hline Unspecified & 0.715 & 0.305 & 2.341 & 2.04 & $1.12,3.72$ & $0.019 *$ \\
\hline University education & -0.01 & 0.189 & -0.055 & 0.99 & $0.68,1.44$ & 0.956 \\
\hline Disability/long term & 2.525 & 0.255 & 9.915 & 12.49 & 7.58 & $0.000 *$ \\
\hline illness status & & & & & 20.58 & \\
\hline $\begin{array}{l}\text { Proximity to } \\
\text { contamination site }\end{array}$ & 0.308 & 0.143 & 2.154 & 1.36 & $1.03,1.80$ & $0.031^{*}$ \\
\hline Sense of place & 0.084 & 0.047 & 1.789 & 1.09 & $0.99,1.19$ & 0.074 \\
\hline \multicolumn{7}{|l|}{ Contamination type } \\
\hline Hydrocarbon & 0.830 & 0.232 & 3.581 & 2.29 & $1.46,3.60$ & $0.000 *$ \\
\hline Heavy metal & 1.044 & 0.27 & 3.860 & 2.84 & $1.67,4.83$ & $0.000 *$ \\
\hline Chlorinated Solvent & 1.345 & 0.305 & 4.413 & 3.84 & $2.11,6.98$ & $0.000 *$ \\
\hline Waste & 0.186 & 0.313 & 0.594 & 1.2 & $0.65,2.22$ & 0.552 \\
\hline
\end{tabular}

Note. $\mathrm{SE}=$ standard error, $\mathrm{OR}=$ odds ratio, $\mathrm{CI}=$ confidence interval

$*_{p}<0.05$ is significant 